\title{
Review: clonidine is more effective than placebo for long term smoking cessation, but has side effects
}

Gourlay SG, Stead LF, Benowitz NL. Clonidine for smoking cessation. Cochrane Database Syst Rev 2004;(3):CD000058.

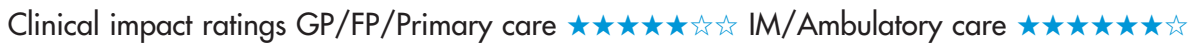

Is oral or transdermal clonidine more effective than placebo for achieving long term smoking cessation?

\section{METHODS}

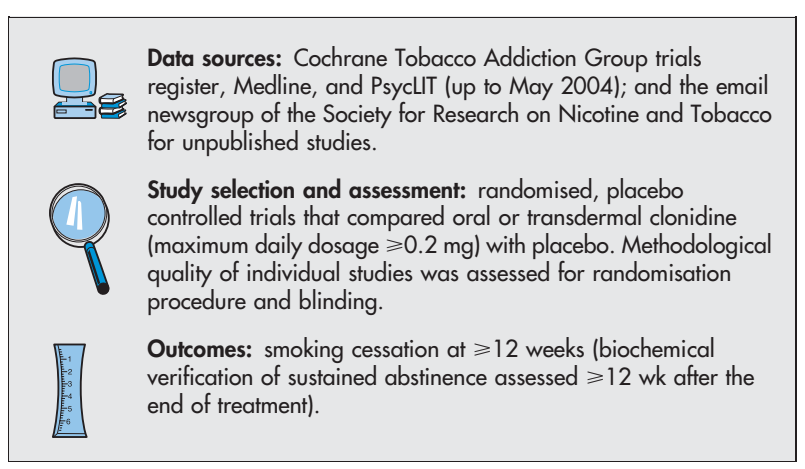

\section{MAIN RESULTS}

6 trials $(\mathrm{n}=776)$ met the inclusion criteria. Assessment of blinding and details of the randomisation procedure were not reported in any of the studies. 4 of the 6 trials used biochemical verification of smoking abstinence using plasma cotinine $(<15 \mu / \mathrm{ml})$, salivary cotinine $(<20 \mu / \mathrm{ml})$, expired carbon monoxide $(<10 \mu \mathrm{ppm})$, or random plasma thiocyanate monitoring. Volunteer participants were recruited from community settings $(5$ trials) and an internal medicine clinic, and were described as smokers ( $>10$ cigarettes/d, 2 trials) or heavy smokers ( $>20$ cigarettes/d or $>1$ pack/d for 3 years, 4 trials). Clonidine was taken orally (dosage varied from a maximum of $0.15-0.45 \mathrm{mg} / \mathrm{d}$ ) (3 trials) or transdermally (dosage $0.1-0.3 \mathrm{mg} / \mathrm{d}$ ) ( 3 trials). Dosage was individualised according to tolerance or body weight, and built up before quit day. Participants in 5 trials received behavioural therapy or counselling, and 1 trial randomised half the clonidine and control groups to behaviour therapy. More patients who received clonidine stopped smoking than did those who received placebo (table). However, clonidine was associated with such dose dependent side effects as dry mouth and sedation.

\section{CONCLUSION}

Oral or transdermal clonidine is more effective than placebo for achieving long term smoking cessation but is associated with side effects including dry mouth and sedation.

For correspondence: Dr S Gourlay, Genentech Inc, South San Francisco, CA USA. goo@gene.com

Sources of funding: National Heart Foundation Australia; US Public Health Service; NHS Research and Development National Cancer Programme.

Abstract and commentary also appear in ACP J Club.

\section{Commentary}

A Ithough clonidine has been used to treat the symptoms of withdrawal for several decades, ${ }^{1}$ its use for smoking cessation has only recently been recommended. The systematic review by Gourlay et al supports the conclusions of a US Public Health Service clinical guideline on treating tobacco use and dependence. ${ }^{2}$ Clinicians should now have confidence that clonidine, along with nicotine replacement therapy (NRT) (gum, patch, inhaler, intranasal spray, or tablets) and antidepressant therapy (bupropion or nortriptyline), is an effective option for helping tobacco users quit.

Clonidine is best for patients who have agitation or anxiety that is unrelieved by NRT or antidepressants, and should be specifically considered when treating patients with withdrawal symptoms who use multiple drugs (eg, opiates, benzodiazepines, or alcohol).

Clonidine is considered a "second line" medication for several reasons. Special care should be taken when prescribing clonidine to older patients because of such well known side effects as drowsiness, dry mouth, and postural hypotension. The dose should be tapered at the end of therapy to avoid the withdrawal effects of clonidine itself. Although the level of evidence for effectiveness is high, only data from 1 of the 6 small studies that were pooled showed a statistically significant difference. The US Food and Drug Administration considers the use of clonidine for tobacco cessation to be an "off label" indication.

While it is not clear which dose or route of administration is the most effective, oral dosing has the added attraction of being relatively inexpensive $(<50 \% / d)$ compared with NRT or bupropion, which can cost $>\$ 3.00 /$ day.

All the studies in the review by Gourlay et al included substantial amounts of behavioural support, which underscores the imperative that clinicians should always focus on behaviour change issues when addressing tobacco dependence.

Helping patients quit smoking is one of the most important things that healthcare providers can do. While clonidine may not be for everyone, it might be useful for patients who have extreme withdrawal symptoms or for those who do not improve with nicotine replacement or antidepressant therapy.

Charles J Bentz, MD Providence | St Vincent Hospital and Medical Center Portland, Oregon, USA

1 Roehrich H, Gold MS. Clonidine. Adv Alcohol Subst Abuse 1987;7:1-16.

2 Fiore MC, Bailey WC, Cohen SJ, et al. Treating tobacco use and dependence. Clinical Practice Guideline. Rockville, MD: U.S. Department of Health and Human Services; June 2000. http://www.ncbi.nlm.nih.gov/ books/bv.fcgi? rid = hstat2. chapter.7644 (accessed Dec 1, 2004).

Clonidine $v$ placebo for smoking cessation at $\geqslant 12$ months $^{*}$

\begin{tabular}{lllllll}
\hline \multirow{2}{*}{ Number of trials } & & \multicolumn{2}{l}{ Weighted event rates } & & \\
\cline { 2 - 5 } & Number of patients & Clonidine & Placebo & RB (95\% CI) & NNT (CI) \\
\hline 6 & 776 & $23 \%$ & $14 \%$ & $63 \%(22$ to 118$)$ & 12 (7 to 25) \\
\hline
\end{tabular}

*Abbreviations defined in glossary; weighted event rates, RBI, NNT, and Cl calculated from data in article using a fixed effects model. 